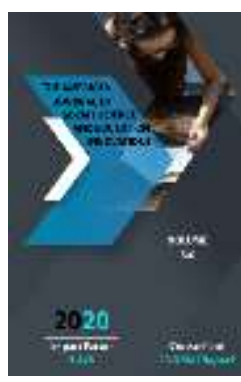

Journal Website: http://usajournalshub.c om/index,php/tajssei

Copyright: Original content from this work may be used under the terms of the creative commons attributes 4.0 licence.

\section{Features Of The Formation Of Perception In The Depiction Of Psychological Portraiture}

Khaitov Zufar Asroralievich

Lecturer, Termez State University, Uzbekistan

Karimova Barchinoy Ilkhom Qizi

Student Termez State University, Uzbekistan

Mamarajabova Shamsiqamar Nishon Qizi

Student Termez State University, Uzbekistan

Jovgashov Obit Rustam Oglu

Student Termez State University, Uzbekistan

\title{
ABSTRACT
}

The features of the formation of perception are considered in the depiction of psychological portraiture.

\section{KEYWORDS}

Psychological portrait, composition, perception, holistic perception

\section{INTRODUCTION}

It is very significant to study and analyze the history, values, science and culture of the peoples of Uzbekistan. Currently, as a result of successive reforms in our country, it is important to build up the potential of the country's intellectual resources by creating and further improving the software and methodological support for organizing education in higher education, training teachers of fine arts based on domestic and world educational experience. "Further improvement of the continuing education system, increasing the potential of high-quality educational services, continuing the policy of training highly qualified personnel in accordance with the modern needs of the 
labor market "plays a significant role in the Strategy of Actions for the Further Development of the Republic of Uzbekistan [ 6 . 39].

It is very interesting to describe a human face, it teaches people to know his character from the face, limbs, structure, color, states of movement of the human body, voice, laughter and so on.

\section{THE MAIN FINDINGS AND RESULTS}

In China, in Europe, the art of reading human figures has been used as a science since ancient times. This science is called physiognomy[7].

In the spiritual heritage of our ancestors, our ancestors, longing for this art and science, came to the conclusion that it is possible to learn their character and traits from the external signs in the form of people (portraits). The stories of Aristotle, Plato, and Luqman Hakim also state that a person can be known by his appearance [8.3]

Kamoliddin Hussein Waz Kashifi, who lived in the 15th century, is the only Central Asian scholar who studied the art of face reading. According to the great scholar's work "Akhlaqi Muhsiniy", the curvature of the tooth is a sign of deceit, betrayal, and the openness and smoothness of the tooth is a sign of justice and entrepreneurship. The fact that the face is full of flesh and thick is a sign of ignorance (hui) speed. It is said that shaking hands when speaking is a sign of intelligence and entrepreneurship.

Shamsiddin Dunasari's book, "The Science of Knowing Man", contains observations gathered in the East about the identity of a person based on the movement of his body, limbs, the structure and color of his face, his breathing, his voice, and even his laughter. He says: - If you know a person's character, nature, elegance, shape, you will begin to understand his good and bad. It will definitely be a great benefit in life, protecting you from disasters. With the guidance of this science, one becomes aware of these shortcomings of oneself and is expected to have bad qualities. He will be aware of the guilt of other people and will be safe from their harm.

Light falling on an object contains many gradations. What we perceive depends on whether the light shines in that color and on the reflectance characteristic of that surface. Affects the retina as a reversible color flow. Brightness and illumination are of particular interest in the study of color issues in the practice of teaching painting. An exact object looks completely different in the shadow and in the light according to its perception of light. When identifying lights in painting, it is important to know that the range of brightness in nature is enormous, while the waist is 20-30 times brighter than black paint. However, the visible brightness is not directly proportional to the brightness of the stimulus, and as a result, perception is limited to a limited degree of brightness of objects.

The decrease in the brightness of the white surface in the etude is mainly due to the fact that the lighting in the workshop where the etude is performed is lower than the illumination on a sunny day in the lap of nature. In nature, black objects or shadows are placed at different angles to light rays and can be placed at different planes relative to white and light surfaces, thus avoiding exposure to sunlight and maintaining a strong contrast to illuminated white surfaces. 
The palette of paints is quite limited in the range of light, while at the same time offering a large range of possibilities in figurative representation of natural conditions. It should be noted that in painting, light is determined by the relationships between all participants in the image, thus forming an image of a particular state of the model in the perception of the relationships obtained convincingly. The artist knows how to move the level of illumination in nature to the range of the paint palette, a skill that allows the etude to perceive light in terms of the harmony of relationships between lights, rather than absolute brightness. Perception of the brightness of objects is further complicated by the fact that the senses of seeing light are not proportional to brightness. In this respect Weber-Fexner's psychophysical law is of particular interest, in which it is stated that the intensity of visual perception increases in arithmetic progression as light increases in geometric progression depending on the true power of light. This law is only valid for medium brightness. It should also be noted that it only determines the tendency of visual perception to increase relatively little in relation to the stimulus itself in an environment. In the practice of working from nature, this is very rare, and often we observe large differences in the tone gradations of the surrounding background.

A key indicator of writing skills is finding expressive color relationships that are often associated with the emotional state of the artist. It characterizes three more and more serious components: 1) emotional experiences from the object of the image; 2) emotional forgiveness of the image process itself; 3 ) the emotional state of the artist in the perception of reality and in the process of visual activity.
Artistic perception is formed consistently and gradually, it develops from elementary and simple forms to relatively complex ones. In the research of E.M. Torshilova and M.Z. Dukharevich there are several levels of development of artistic cognition: Level 1 holistic perception, which is characterized by the absence of image expressiveness, imagery, emotionality. This perception can be assessed as simple. Level 2 - A level that is insufficient for full-fledged visual activity is characterized by the emergence of an idea. Realistic tendencies begin to appear in the image, but line and spot capture are not perfected, attitudes toward the world become aesthetic, and elementary forms of experience emerge. Level 3 - at this level of development of intuitive-emotional, artistic perception, along with the existing pictorial idea, there is an accentuation of the character of the simplest form, the means of expression are imperfect the form of aesthetic experiences remains elementary. For this level, which is sufficient for level 4 visual activity it is typical to transfer experiences from real reality through their own inner world, using the accumulated experience, although the creative originality of the idea is often spontaneous. Cognitive integrity is formed on the basis of the analysis and synthesis of impressions and perceptions of reality. The need for more complex forms of aesthetic experiences emerges at a greater level of empathy. The arsenal of means of expression, though not perfect, is growing. Level 5 - intellectual artistic - this level of development of artistic perception is based on the understanding of the laws of nature, life experience, knowledge and skills acquired in the field of fine arts. Significant improvement of the technical image: mastery of lines, spots, shape, color, organization of the image environment in space, etc. observed. Artistic perception is 
characterized by imagery, considerable integrity, and a tendency to seek new creative ways in the image. Aesthetic evaluation acquires a certain depth, but does not find its adequate figurative expression. Level 6 - an adequate level of artistic perception - is a holistic emotional-figurative perception that is painted with aesthetic evaluation. The idea fits into the creative process.

\section{CONCLUSION}

The study of the issues of artistic perception in handwriting is inextricably linked with the concept of tone. In artistic practice, tone is often characterized by the brightness of the colors transmitted. However, tone in painting is considered not only in a narrow sense, the tone realized on the surface of the image is understood as a whole complex of the artist's associations.

\section{REFERENCES}

1. Baymetov B. "Pencil drawing". Textbook Part 1.- Tashkent: Music 2006

2. Khalilov R. Drawing. Toshkent "Navruz" 2013.

3. Kuzin B.C. Psychology. Textbook. Moscow: Agar, 1997. - p. 304., ill.

4. Kuzin B.C. Questions of fine art. Moscow: Education, 1971. -FROM. 144.

5. Labunskaya G.V. Fine art of children. Moscow: Education, 1965. - p. 207.http: //www.edu.uz

6. Decree of the President of the Republic of Uzbekistan "On the strategy of further development of the Republic of Uzbekistan".// Collection of laws of the Republic of Uzbekistan. Tashkent: 2017. - p. 39.

7. Higir B.Yu. Physiognomy. Moscow: S. Petersburg: DILYA, 2000.
8. Shamsiddin Muhammad ibn Amiruddin Dunasaray. The science of knowing a person, Translation from Persian-Tajik by B.Omon. Tashkent: Writer, 1994. -p. 3. 